\title{
Burden Of Cysts And Tumors Around Impacted Third Molars
}

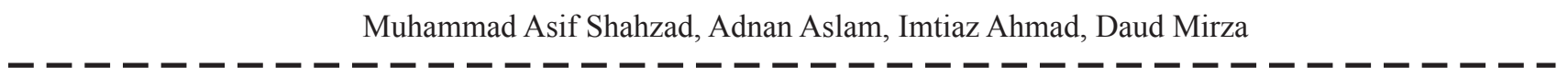

ABSTRACT:

Objective: To assess the frequency of cysts and tumors around impacted third molars.

Study Design and Setting: Cross-sectional study was conducted at the OMFS department, Lahore Medical \& Dental College, from August 2015 to January 2018.

Methodology: A total of 2057 patients were operated for the removal of 2354 impacted third molars and analyzed for their associated pathological lesions(cysts/tumors). Patients were evaluated with thorough history, clinical and radiological examination. Panoramic and periapical radiographs were primarily used to assess the site of third molar impactions (maxilla/mandible) and their associated pathologies confirmed with histopathological examination. Data was analyzed using SPSS version 20.

Results: The patients' ages were between 17 to 62 years (Mean \pm SD, 28.12 \pm 8.585$)$. There were $n=709(34.47 \%)$ females and $n=1348(65.53 \%)$ male with female to male ratio of 1.9:1. The mandibular to maxillary impacted third molars ratio was $1.66: 1$. An overall frequency of $1.36 \%$ for cysts and $0.72 \%$ for tumor associated with impacted third molars was demonstrated in the current study. The most frequently diagnosed cyst was dentigerous whereas ameloblastoma was the most commonly identified tumor.

Conclusion: A relatively lower frequency $(2.08 \%)$ of pathological lesions was found around third molars. The study reported a smaller number of pathological lesions affecting a significant minority of patients. It is recommended that a dentist/oral maxillofacial surgeon should be consulted at the earliest if any symptoms in the third molar region arise along with imaging of the area.

Key words: Ameloblastoma, dentigerous cyst, pathological lesions, third molars,.

\section{INTRODUCTION:}

The third molar is the most common tooth to become impacted ${ }^{1}$. There have been different hypotheses behind why the third molars are the most commonly impacted teeth $^{2}$. Impacted third molars display a range of anatomical variation in terms of their pattern and position and can lead to a hoist of often diverse pathological occurrences ${ }^{3,4}$. Despite being of little benefit in terms of function, the question whether they should be removed is contentious and the debate is still continues ${ }^{5,6}$.

A number of studies conducted worldwide have emphasized on the removal of impacted third molars irrespective of presence of any symptoms or associated pathologies ${ }^{7,8,9}$. While, on the contrary, recent literature have advocated that

Muhammad Asif Shahzad, I Associate Professor, Department of Oral \& Maxillofacial | I Surgery, Lahore Medical \&Dental College, Lahore.

IEmail: drasif_395@hotmail.com

Adnan Aslam,

Associate Professor, Department of Oral \& Maxillofacial I Surgery, MargallaInstitute of Health Sciences, Rawalpindi.

Muhammad Imtiaz,

I Assistant Professor, Department of Oral \& Maxillofacial I

I Surgery, FMH College of Medicine \& Dentistry, Lahore

I Daud Mirza

I Associate Professor, Department of Oral Pathology,

Bahria University Medical and Dental College, Karachi

I Received: 03-08-18

Accepted: 15-02-19 removal of asymptomatic impacted third molar is not essential, keeping in view the relatively low risk of development of pathologies around these teeth ${ }^{10,11}$. However, another group of researchers concluded that removal of asymptomatic third molars is still controversial and dubious because of paucity of reliable data regarding the frequency of pathologies associated with these third molars ${ }^{12,13,14}$.

The objective of this current study was to observe the frequency of cysts and tumors around the impacted third molars

\section{METHODOLOGY:}

This cross-sectional study was conducted from August 2015 to January 2018 at the department of oral maxillofacial surgery (OMFS), Lahore Medical \& Dental College, Lahore, a total of 2057 patients were operated for the removal of 2354 impacted third molars. The patients of both gender and age 17 years or older having clinical or radiological evidence of complaint/pathology associated with third molars were included in the present study. While selecting the patients, the normal third molar eruption time/age was kept in view. Patients having historyof maxillofacial trauma, any associated systemic orcraniofacial anomaly or syndrome, were excluded.

The patients, who came to our unit as a primary care setup or referred by dental practitioners, were first evaluated in the Oral Diagnosis department according to the institute protocol. Patients having their presenting complaint associated with impacted third molars and those who showed clinical 
$\&$ radiographic findings of associated pathology were referred to Oral and Maxillofacial Surgery Department for further evaluation and management.

For each patient, the assessment of impacted third molars and their associated pathologies/radiolucency was done by a thorough history, clinical examination and radiographs, including periapical and panoramic views, according to departmental protocol. CT/CBCT scans were prescribed if needed. On pericoronal radiographs; the radiolucency measuring $<4 \mathrm{~mm}$, representing follicular space, was taken as normal. Patients' demographic details (age and sex), site of impaction and associated pathologies/radiolucency (maxilla/mandible) were recorded (Figure 1,2 ).

The patients having clinical and radiographic evidence of impacted third molar associated pathologies/radiolucency were informed about their lesion and an informed consent was taken for the biopsy procedure (incisional/excisional) to obtain the specimen under local anesthesia. For histopathological examination, the specimen was sent to Department of Oral Pathology and only after histopathological report; the diagnosis for cyst and tumor was confirmed.

The data collected was analyzed using SPSS version 20. The qualitative variables like gender, side of impaction, and associated pathologies were presented as frequency and percentages. Quantitative variables were presented as mean and standard deviation. With a confidence interval of $95 \%$, the value of $p<0.05$ was considered significant. We did not apply any inferential test as the study was descriptive in nature.

\section{RESULTS:}

Over a 29 months period from August 2015 to January 2018 at the Department of OMFS, LMDC, Lahore, 2354 impacted third molars in 2057 patients were removed.

The patients' ages were between 17 to 62 years (Mean $\pm \mathrm{SD}$, $28.12 \pm 8.585)$. There were 709 females and 1348 male with female to male ratio of $1.9: 1$. The mandibular to maxillary impacted third molars ratio was 1.66:1.

There were $n=32$ cysts $(1.36 \%)$ and $n=17$ tumors $(0.72 \%)$, that were found associated with 2354 impacted third molars.

Among the 32 patients who were identified as having cysts, there were $\mathrm{n}=14(43.75 \%)$ females and $18(56.25 \%)$ male. The ages of these patients were between 18 to 62 years(mean, $31.19)$. There were $n=9(28.12 \%)$ localized in maxilla and $23(71.88 \%)$ in mandible. Out of these, $21(65.63 \%)$ were found to be dentigerous cysts, 09 (28.12\%) odontogenic keratocysts and $2(06.25 \%)$ were identified as calcifying cysts (odontogenic) ( Table 1\&2).

A total of 17 patients were diagnosed as having tumors associated with third molars. There were 9 (52.94\%) females and $8(47.06 \%)$ males. Their ages ranged from 17 to 53(mean, 29.47 years). Among the 17 tumors, the maxilla was involved in $3(17.65 \%)$ while the mandible was affected in $14(82.35 \%)$ patients. There were $11(64.71 \%)$ ameloblastomas, 02 (11.77\%) odontogenicmyxomas, $2(11.76 \%)$ calcifying epithelial odontogenic tumor, $1(5.88 \%)$ ameloblastic fibromas and $01(05.88 \%)$ odontoma. No malignant tumor was found in our study. (Table $3 \& 4$ )

An overall frequency of $1.36 \%$ for cysts and $0.72 \%$ for tumor associated with impacted third molars was demonstrated in the current study. The most frequently diagnosed cyst was dentigerous where as ameloblastoma was the most commonly identified tumor.

\begin{tabular}{|l|c|c|}
\hline Types of Cysts & $(\mathbf{n}=\mathbf{3 2})$ & $\mathbf{\%}$ \\
\hline Dentigerous cyst & 21 & 65.63 \\
\hline Odontogenickeratocyst & 09 & 28.12 \\
\hline Calcifying odontogenic Cyst & 02 & 06.25 \\
\hline
\end{tabular}

Table 1: Frequency Of Cysts Around Impacted Third Molars

\begin{tabular}{|l|c|c|c|c|}
\hline & \multicolumn{2}{|c|}{ Site } & & \\
\hline Gender & $\begin{array}{c}\text { Maxilla } \\
\mathrm{n}\end{array}$ & $\begin{array}{c}\text { Mandible } \\
\mathrm{n}\end{array}$ & Total & $\mathbf{\%}$ \\
\hline Female & 03 & 11 & 14 & 43.75 \\
Male & 06 & 12 & 18 & 56.25 \\
\hline
\end{tabular}

Table 2: Gender and site distribution of cysts

\begin{tabular}{|l|c|c|}
\hline \multicolumn{1}{|c|}{ Tumors } & $(\mathrm{n}=17)$ & $\%$ \\
\hline Ameloblastoma & 11 & 64.71 \\
\hline $\begin{array}{l}\text { Calcifying epithelial } \\
\text { odontogenic tumor }\end{array}$ & 02 & 11.77 \\
\hline Odontogenicmyxoma & 02 & 11.76 \\
\hline Ameloblastic fibroma & 01 & 05.88 \\
\hline Odontoma & 01 & 0.588 \\
\hline
\end{tabular}

Table 3: Frequency Of Tumors Around Impacted Third Molar

\begin{tabular}{|c|c|c|c|c|}
\hline Gender & $\begin{array}{c}\text { Mandible } \\
\text { (Patients No.) }\end{array}$ & $\begin{array}{c}\text { Maxilla } \\
\text { (Patients No. })\end{array}$ & Total & Percentage \\
\hline Female & 08 & 01 & 09 & 52.94 \\
\hline Male & 06 & 02 & 08 & 47.06 \\
\hline
\end{tabular}

Table 4: Gender And Site Distribution Of Tumors

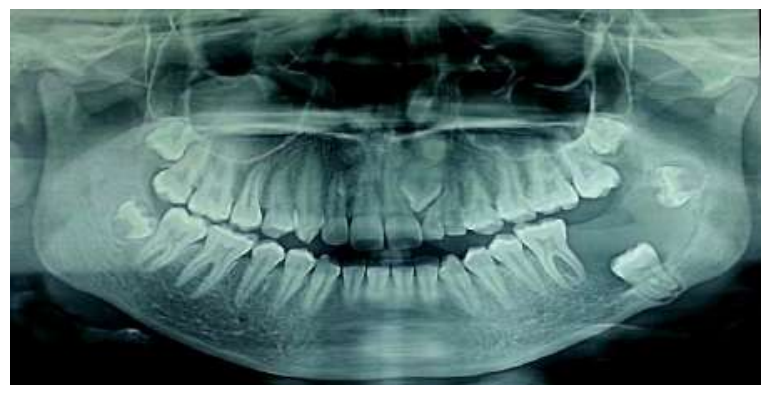

Figure 1: Radiograph showing a radiolucent lesion in left mandible diagnosed as dentigerous cyst after histopathological examination. 


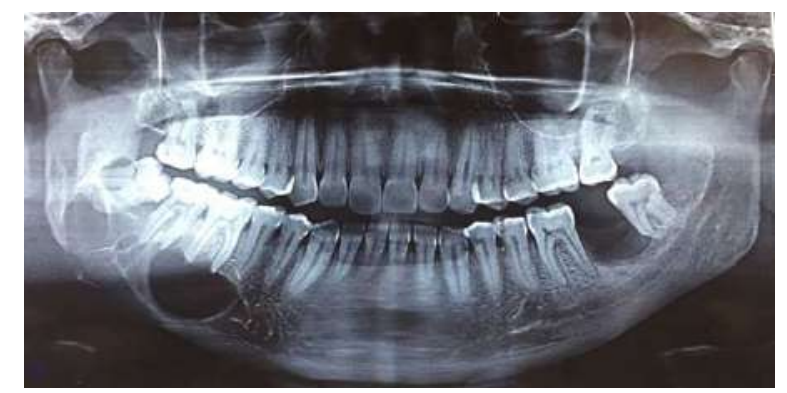

Figure 2: Radiograph showing a multilocular radiolucent Lesion in right mandible diagnosed ameloblastoma after histopathological examination.

\section{DISCUSSION:}

Impacted third molars display a range of anatomical variation in terms of their pattern and position, and can lead to a hoist of often diverse pathological occurrences ${ }^{3,4}$. The question whether they should be removed is contentious/dubious and a debate over this still continues ${ }^{12,14}$.

Most of the literature regarding the incidence and frequency of cysts and tumors around third molars has shown and documented a significant variation according to the patient's age and the population being studied. The studies performed by Mourshed ${ }^{15}$ and Shear ${ }^{16}$ have reported and revealed a lower incidence of $1.44 \%$ and $0.001 \%$ respectively regarding the cysts $\&$ tumors around impacted third molars. These recorded findings are in accordance and supported by the studies executed by Goldberg ${ }^{17}$ and Chiapasco ${ }^{18}$ who demonstrated a frequency of $2 \%$ and $1.5 \%$ respectively. While Guven ${ }^{19}(2.31 \%)$ and Lysell ${ }^{20}(3 \%)$ have almost highlighted the same results. On the contrary, Nordenram ${ }^{21}$ $(4.5 \%)$ and $\operatorname{Dachi}^{22}(11 \%)$ have reported a relatively higher incidence in their conducted studies. The current study has revealed a frequency of $1.36 \%$ of cyst development around impacted third molars. These findings are comparable and corroborated by the studies done by Chiapasco ${ }^{18}(1.5 \%)$ and Mourshed $^{15}(1.44 \%)$ among others who also documented the similar results.

On the other side, the findings of a study done Bruce $^{23}$ has exposed that frequency of cyst development around third molars is an age dependent phenomenon which varies significantly among different age groups. He demonstrated and documented an overall incidence of $6.2 \%$ with a lower incidence $(1.5 \%)$ in the younger age group with a mean age of 20 year whereas the highest incidence was recorded in the older age group with a mean age of 46.5 years. Girod ${ }^{24}$ in his executed study identified that the progression and eventual development of cysts around third molars is a time related process. He advocated a possible assumption that the impacted third molars persisting for a longer period (2-13 years) might have an increased risk of developing a pathologic lesion (cyst/tumor).

To differentiate a hyperplastic follicle (dental) from an earlier dentigerous cyst, at times, can be difficult as no uniform and definite criteria for their differential diagnosis has been set and popularized and still controversy does exist. In this regard, Kotrashetti $\mathrm{i}^{25}$ conducted a study in 115 asymptomatic healthy patients having 120 impacted third molars. He reported that dentigerous cyst was identified in $1.1 \%$ of patients, while odontogenickeratocyst and calcifying cyst (odontogenic) were found in $2.5 \%$ and $6.6 \%$ of patients respectively. Follicular epithelium was diagnosed to be normal in the remaining patients.

Stoelinga ${ }^{26}$, on the other hand, regarding a study on keratocysts hypothesized and revealed that these pathological lesions emanate either from the epithelial proliferation of overlying oral mucosa or offshoots/remnants of dental lamina.

Regarding the incidence and frequency of tumor development around third molars, Lysell et al ${ }^{20}$ reported a figure of less than $1 \%$. Their findings were reinforced by Regezi ${ }^{27}$ who also found an incidence of $0.14 \%$. The results of Shear ${ }^{16}$ $(2 \%)$ and $\mathrm{Weir}^{28}(2 \%)$ were also in harmony with that of Lysell and Regezi. In the current study, we found a frequency of $0.79 \%$ for tumor developing around third molars which is in agreement with the results shown by $\operatorname{Regezi}^{27}$ and Lysell ${ }^{20}$.

The development of malignant tumor associated with impacted third molars is a rare phenomenon ${ }^{29,30}$. Only 2 cases of malignant tumors, with an incidence of $0.02 \%$, were recorded in a study done by Guven ${ }^{19}$. However, we were not able to diagnose and find any case of malignancy in our study.

The decision regarding the removal of third molar or not is dependent on the patient compliance as well as local circumstances; which may influence the policy regarding impacted third molars. This in turn will help to prioritize treatment in patients with such pathologies and rationalize decision making in relation to removal of impacted third molars. A regular follow up along with imaging of the third molar region is of utmost importance while adopting a wait and see policy. This fact has been corroborated and advocated by recent literature in worldwide conducted studies. It is recommended that a dental/oral surgeon should be consulted at the earliest, if any symptoms in the third molars region arise, along with regular follow up.

\section{CONCLUSION:}

This study concluded a relatively lower frequency $(2.08 \%)$ of pathological lesions around third molars. An overall frequency of $1.36 \%$ for cysts and $0.72 \%$ for tumor associated with impacted third molars was demonstrated in the current study. The most frequently diagnosed cyst was dentigerous whereas ameloblastoma was the most commonly identified tumor.The study also highlighted that although a smaller number of pathological lesions were reported but still affecting a significant minority of patients. 


\section{REFERENCES:}

1. Secic S, Prohic S, Komsic S, Vukovic A. Incidence of impacted mandibular third molars in population of Bosnia and Herzegovina: a retrospective radiographic study. J Health Sci.2013;3:151-8.

2. Juodzbalys G, Daugela P. Mandibular third molar impaction: Review of literature and a proposal of a classification. J Oral Maxillofac Res. 2013;4:1-12.

3. Ayaz H, Rehman A. Pattern of impacted mandibular third molar in patients reporting Department of Oral and Maxillofacial Surgery, Khyber College of Dentistry, Peshawar. J KhybColl Dent. 2012;2:50-3.

4. Vigneswaran AT, Shilpa S. The incidence of cysts and tumors associated with impacted third molars. J Pharm Bioall Sci. 2015;7:251-4.

5. Krishnan B, El Sheikh MH, El-Gehani R, Orafi H. Indications for removal of impacted mandibular third molars: a single institutional experience in Libya. J Maxillofac Oral Surg. 2009;8:246-8.

6. Motazavi H, Baharvend M. Jaw lesions associated with impacted tooth. A radiographic diagnostic guide.ImagingSci Dent. 2016;46:147-57.

7. Steveo ELL, Baih MS. Are impacted third molars always necessary to be removed? Adv Dent \& Oral Health. 2016.

8. Shahzad MA, Marath MA, Chatha MR, Sohail A. Evaluation of patterns of mandibular third molar impactions and associated pathologies. Pak Oral Dent J. 2016;36:192-6.

9. Amanat N, Mirza D,Rizvi KF. Pattern of third molar impaction: frequency and types among patients attending urban teaching hospital of Karachi. Pakistan Oral \& Dental Journal, 2014; 34(1):34-37.

10. Braimah RO, Ibukunle AA, Taiwo AO, Ndukwe KC, Owotade JF, Aregbesola SB. Pathologies associated with impacted third molars in sub-Saharan African. Dent Med Res. 2018;6:2-6.

11. Campbell JH. Pathology associated with the third molar. Oral MaxillofacSurgClin North Am 2013;25:1-10,

12. Mukherji A, Singh MP, Nahar P, Balaji BS, Mathur H, Goel S. Predicting pathology in impacted mandibular third molars. J Indian Acad Oral Med Radiol. 2017;29:20-4.

13. Kostopoulou O, Brickley MR, Shepherd JP, Newcombe RG, Knutsson K, RohlinM.Intra-observer reliability regarding removal of asymptomatic third molars. Br Dent $J$. 1998;184:557-9.

14. Stathopoulos P, Mezitis M, Kappatos C, Titsinides S, Stylogianni E.. Cysts and tumors associated with impacted third molars: is prophylactic removal justified? J Oral MaxillofacSurg. 2011;69:405-8.

15. Moushed FA. Roentgenographic study in detecting dentigerous cysts in the early stages. Oral Surg. 1964;18:54-61.
16. Shear M, Singh S. Age standardized incidence rates of ameloblastoma and dentigerous cyst on the Witwatersrand South Africa. Community Dent Oral Epidemiol. 1987;6:1959 .

17. Goldberg MH, Nemerich AN, Marco WR. Complications after mandibular third molar surgery: a statistical analysis of 500 consecutive procedures in private practice. J Am Dent Assoc. 1985;3:277-9.

18. Chiapasco M, De Ciccol, Marrone G. Side effects and complications associated with third molar surgery. Oral Surg. 1993;76:41-9.

19. Guven O, Keskin A, Akal UK. The incidence of cysts and tumors around impacted third molars.Int J Oral Maxillofacsurg. 2000;29:131-35.

20. Krishnan B, Sheikh MH, Rafa el-G, Orafi H. Indications for removal of impacted mandibular third molars: a single institutional experience in Libya. J Maxillofac Oral Surg. 2009;8(3):246-8.

21. Nordenram A, Hultin M, Kjellman O, Ramstrom G. Indication for surgical removal of third molars: study of 2630 cases. Swed Dent J. 1987;11:23-9.

22. Dachi SF, Howell FV. A survey of 3,874 routine full mouth radiographs. II: A study of impacted teeth. Oral Surg. 1961: 14:1165-9.

23. Bruce RA, Fredrickson GC, SmallGS. Age of patients and morbidity associatedwith mandibular third molarsurgery. J Am Dent Assoc. 1980;101:241-5.

24. Girod SC, Gerlach KL, Krueger G. Cysts associated with long-standing impacted third molars. Int J Oral MaxillofacSurg. $1993 ; 22: 110-2$

25. Kotrashetti VS, Kale AD, Bhalaerao SS, Hellikeremath SR. Histopathological changes in soft tissue associated with asymptomatic impacted third molars. Indian J Dent Res. 2010;21:385-390.

26. Stoelinga PJW, Bronkhorst FB. The incidence, multiple presentation and recurrence of aggressive cysts of the jaws.JCraniomaxillofacSurg. 1988;16:184-95.

27. Regezi JA, Kerr DA, Courtnex RM. Odontogenic tumors: analysis of 706 cases. J Oral Surg. 1978;36:771-8.

28. Weir JC, Davenport WD, Skinner RL. Diagnostic and epidemiologic survey of 15,783 oral lesions. J Am Dent Assoc. 1987;115:439-42.

29. Borrás-Ferreres J, Sánchez-Torres A, Gay-Escoda C. Malignant changes developing from odontogenic cysts: A systematic review. J ClinExp Dent. 2016;8(5):e622-e628. Published 2016 Dec 1. doi:10.4317/jced.53256

30. Maria A, Sharma Y, Chhabria A. Squamous cell carcinoma in a maxillary odontogenickeratocyst: a rare entity. Nat J MaxillofacSurg. 2011;2:214-18. 